\title{
Blood donation barriers: How does donor profile affect them?
}

\author{
Laura Romero-Domínguez ${ }^{1}$ (D) - Josefa D. Martín-Santana ${ }^{1}$. \\ Agustín J. Sánchez-Medina ${ }^{2} \cdot$ Asunción Beerli-Palacio $^{1}$
}

Received: 7 April 2021 / Accepted: 20 June 2021 / Published online: 8 July 2021

(c) The Author(s) 2021, corrected publication 2021

\begin{abstract}
Donation barriers are a crucial factor to consider in the study of blood donor behavior. Since blood donors do not behave homogeneously, the aim of this work is to analyze how the donor profile (i.e. sociodemographic characteristics and donation behavior) influences the prevalence of blood donation barriers. A total of 5,353 active donors in the Canary Islands (Spain) completed an online survey. Given the general lack of agreement concerning the conceptualization and measurement of donation barriers, an integrative 25-item barrier scale, which is the result of grouping all barriers identified in the literature according to the concept of obstacle which they represent, was designed and validated. The results indicate that individuals between 18 and 35 years of age, with university education and higher income are more likely to be affected by donation barriers. At the same time, individuals who donate once or twice a year, and those with shorter experience as donors, are more prone to experience donation barriers. The present study is useful for blood transfusion centers, because it shows that centers must identify which donation barriers are the most prevalent in their donor pool, as well as which donor groups are the most affected by them. Thus, blood transfusion centers will be able to design appropriate marketing actions to reduce or eliminate those barriers that prevent active donors to donate repetively.
\end{abstract}

Keywords Blood donation · Barriers · Donor profile $\cdot$ Sociodemographics · Donation behavior

Laura Romero-Domínguez

laura.romero@ulpgc.es

1 Universidad de Las Palmas de Gran Canaria, Campus universitario de Tafira s/n, 35017 Las Palmas de Gran Canaria, Las Palmas, Spain

2 Instituto Universitario de Ciencias y Tecnologías Cibernéticas (IUCTC), Parque Científico Tecnológico, Campus Universitario de Tafira, 35017 Las Palmas de Gran Canaria, Las Palmas, Spain 


\section{Introduction}

For decades, healthcare systems have faced a declining blood donor pool, leading to an imbalance between blood supply and demand (Carter et al., 2011). This is due to factors such as an increase in medical and surgical interventions, an ageing population, stricter donor selection criteria, and the perishable nature of blood (Solomon, 2012; Vavić et al., 2012). As blood cannot be artificially produced (Moussaoui et al., 2016), the stability of any blood donation system depends on the willingness of voluntary donors (Tey et al., 2020).

Blood transfusion centers ${ }^{1}$ devote great efforts to promote blood donation among the population by using three complementary strategies: retaining active donors, recruiting new donors, and recovering inactive and deferred donors (Godin et al., 2005). The last two strategies contribute to expanding the donor pool, whereas donor retention aims to maintain a stable, safe blood supply. Furthermore, active donors generally experience less donation-related physical reactions (e.g. dizziness, physical weakness or fainting), and their infectious markers are generally lower (Gemelli et al., 2017). Active donors' donation frequency is higher and, given their high commitment to this social cause, they might act as prescriptors (Martín-Santana \& Beerli-Palacio, 2012).

To retain donors, blood transfusion centers must identify which factors stimulate and hamper donation (Rodrigues \& Carlos, 2020). Among them, donation barriers and motivations should be considered. A barrier can be described as any obstacle that prevents or hinders donation (e.g. fear of needles, lack of time, medical conditions), whereas a motivation could be any force or source driving to donate (e.g. prosocial reasons, positive emotions, incentives). The interaction between barriers and motivations explains their simultaneous analysis: when barriers prevail over motivations in terms of quantity and/or intensity, individuals decide not to donate, and viceversa (Hupfer et al., 2005). However, the particular interest on analyzing barriers lies with their impact on donation behavior: while multiple motivations have additive effects on the donation decision, a single barrier might completely prevent a donation attempt (Bednall \& Bove, 2011). This contributes to the fact that the majority of the population does not donate blood, even though they are willing to do so (Huis in 't Veld et al., 2019). These arguments, along with the the fact that barriers have been studied to a lesser extent than motivations, justify the importance of studying barriers when analyzing blood donor behavior.

However, human behavior is naturally heterogeneous. Therefore, the prevalence of donation barriers is expected to differ among individuals, and it depends on other factors such as donors' sociodemographic characteristics and their donation behavior.

\footnotetext{
1 According to Spanish Royal Decree 1088/2005, blood transfusion centers are "health centers where activities are carried out to collect and analyze human blood or their components, regardless of the purpose that they are used for, and to treat, store and distribute them when they are used for transfusion." Blood transfusion centers are framed in the Spanish public national health system. They are also considered non-profit because their main purpose is "to organize and oversee voluntary social action directed at humanitarian problem-solving” (Mokwa, 1990, p. 43).
} 
From a social marketing perspective, which seeks to foster behavioral changes that benefit both individuals and society (Rodrigues \& Carlos, 2020), the variability in how barriers affect donors requires differentiated actions to promote blood donation among the population (Beerli-Palacio \& Martín-Santana, 2015; Polonsky et al., 2015). However, it is common that blood transfusion centers design undifferentiated actions, i.e. they target a same message to the audience as a whole (Sundermann et al., 2017; Trenholm, 2017).

For the aforementioned reasons, the purpose of this study is to analyze how the donor profile influences the prevalence of blood donation barriers. However, the lack of consensus on the measurement tools has required the design of a holistic, integrative barrier scale, whose validity and reliability will be demonstrated.

\section{Theoretical background}

Donation barriers have been widely studied in the literature. The most prominent ones include fear (Zucoloto et al., 2019), inconvenience of donation venues (Schreiber et al., 2006), lack of time (Duboz \& Cunéo, 2010), physical reactions (France et al., 2005), lack of information (Kalargirou et al., 2014) and lack of an explicit donation request (Marantidou et al., 2007). Nonetheless, it is common that different studies attribute different denominations to a same concept of barrier (Piersma et al., 2017). For example, inconvenience. While some authors refer to the time- (i.e. operating hours of donation venues) or the space dimension (i.e. location) when addressing inconvenience (e.g. Hupfer et al., 2005; Klinkenberg et al., 2018; Yuan et al., 2011), other authors consider both dimensions together, describing the act of donating as "inconvenient" without discerning the causes (e.g. Schreiber et al., 2006; Shaz et al., 2010). Additionally, when barriers are categorized, both the number and content of the items in each category also vary among studies. For instance, in Polonsky et al.'s (2015) work, the barrier scale was divided into three descriptive categories: "Cultural and societal issues" (e.g. "Cultural reasons prevent me from donating blood," "My elders do not approve me to donate blood"), "Fear" (e.g. "I am scared of needles") and "Lack of understanding" (e.g. "I do not know where the donation center is"). In constrast, Zaller et al.'s (2005) scale was divided into two categories: "Individual factors" and "Peer factors." Besides differing substantially in size (9 vs. 2 items), these categories included a wide variety of different barriers: fear of needles, the need to leave work to go donate, concerns about the ability of the phlebotomist... To summarize, if no previous consensus exists, the comparison of results between studies becomes a complex issue (Martín-Santana et al., 2020).

Therefore, to fill this gap, this study proposes a holistic, integrative donation barrier scale (refer to Online Resource 1). The 25 barriers included in this scale are the result of grouping all barriers identified in the literature on blood donor behavior. They were grouped according to the concept of obstacle which they represent, despite the aforementioned terminology and expression differences.

As previously mentioned, donors do not experience the same barriers. The barrier prevalence depends on their donor profile (i.e. sociodemographic- and donation behavior characteristics). However, most research on donation barriers has 
studied these individual variables solely from a descriptive perspective (e.g. Bednall \& Bove, 2011; Piersma et al., 2017). Studies that cross-analyze the donor profile with self-reported donation barriers are scarce in literature (e.g. Charbonneau et al., 2016; James et al., 2013).

\subsection{The influence of donor profile on donation barriers}

Online Resource 2 summarizes the results of the studies in which the prevalence of donation barriers has been analyzed according to the donor profile. These results indicate that sex does influence this prevalence. Women report experiencing donation fears (e.g. of sight of blood, of feeling sick) to a greater extent than men (e.g. Kalargirou et al., 2014; Shaz et al., 2010). Besides, previous negative donation experiences prevent female donors from donating again (Charbonneau et al., 2016; Schreiber et al., 2006), as well as the non-compliance with medical requirements for donation (Charbonneau et al., 2016; Hupfer et al., 2005). At the same time, the most prevalent donation barriers in men are those associated with time and space (Bani et al., 2014; Charbonneau et al., 2016).

Regarding age, younger donors ${ }^{2}$ experience more donation-related fears, principally concerns about the safety of the donation process (Kalargirou et al., 2014). In contrast, older donors highlight medical reasons as a significant donation barrier (Charbonneau et al., 2016; Misje et al., 2008; Schreiber et al., 2006). On the other hand, while both age groups report experiencing time-related barriers, these are different. Older donors experience barriers associated with family responsibilities (Charbonneau et al., 2016), while younger donors report that their sport/leisure activities are incompatible with the blood donation centers' schedules, or that they simply do not have time to donate (Charbonneau et al., 2016; James et al., 2013; Misje et al., 2008). In addition, this general lack of time is complemented by the inconvenience of the donation venues, which has been identified as a major barrier for younger donors (Schreiber et al., 2006).

The association between education and donation barriers has received limited attention. Existing studies attribute medical reasons (Charbonneau et al., 2016) and lack of information on where to donate (James et al., 2013) to less educated donors. Conversely, lack of time (Charbonneau et al., 2016; Shaz et al., 2010) and non-compliance with the donation criteria due to travelling to certain countries (Charbonneau et al., 2016) are associated with donors that have a university education.

Finally, the influence of income level on the prevalence of barriers has also been scarcely studied. The few existing studies indicate that individuals with lower income $^{3}$ experience a greater lack of information, greater difficulty in accessing donation venues (James et al., 2013), and greater concern about not being physically able to donate (Shaz et al., 2010) than individuals with higher income.

\footnotetext{
${ }^{2}$ Following James et al. (2013), the cutpoint to describe a donor as young or old is 40 years-old (i.e. younger donors are less than 40 years-of-age).

${ }^{3}$ Following James et al. (2013), an annual income below \$75,000 is considered lower income.
} 
Two conclusions can be drawn from the above-mentioned exposition. Firstly, the existing studies on this topic tend to focus on the same barriers, which fundamentally are those related to fear, lack of time and medical reasons. Many barriers identified in Online Resource 1 have not been considered, and these might be interesting for blood transfusion centers. Secondly, it is evident that the prevalence of certain donation barriers depends on the donor's sociodemographic profile. However, since barriers have been studied under highly different approaches (i.e. terminology, categorizations), it is not possible to propose hypotheses. For this reason, this study establishes the following research question on the relationship between the sociodemographic profile and the prevalence of donation barriers:

Question 1. How does the sociodemographic profile (i.e. sex, age, income and education) influence the prevalence of donation barriers?

As far as donation behavior is concerned, only Beerli-Palacio and Martín-Santana's (2015) research analyzes the relationship between donation frequency and the prevalence of donation barriers. Their results indicate that, compared to occasional- and first-time donors, frequent donors (i.e. individuals who donate at least once a year) experience difficulties in matching their schedules with those of the blood transfusion centers.

Furthermore, the donor experience also affects the prevalence of barriers. As it can be concluded from Online Resource 2, less experienced donors exhibit higher levels of donation-related fears. In contrast, more experienced donors consider lack of time and time-space inconvenience to be the main obstacles to not donating more regularly.

With this in mind, and consistently with the reasoning on the sociodemographic profile, the following research question arises:

Question 2. How does donation behaviour (i.e. donation frequency and donor experience) influence the prevalence of donation barriers?

\section{Methodology}

\subsection{Study population and data gathering}

Data were collected through an online survey from March to September, 2018. The study population comprised active donors (individuals who had donated blood at least once in the last two years) registered in the database of the Canary Institute of Hemodonation and Hemotherapy (Spanish initials: ICHH), which is the responsible institution for blood collection, analysis, distribution and storage in the Canary Islands (Spain). The focus on active donors lies with the fact that, contrary to expected, active donors are also affected by donation barriers, which act as obstacles to donate more frequently (Charbonneau et al., 2016). Taking into account that one paramount objective for blood transfusion 
centers is achieving the highest number of annual donations from these donors (Martín-Santana et al., 2018), analyzing the donation barriers among active donors is fundamental.

All respondents were older than 18 years-old, both sexes, and lived in the Canary Islands. ICHH sent their registered donors an e-mail with the URL that hosted the online survey. After removing 90 unfinished questionnaires, the final sample comprised 5,353 respondents.

\subsection{Measurement instruments}

Besides questions about the sample profile (sex, age, education, total monthly income, donation frequency and donor experience), the online survey included a donation barrier scale. This scale comprised 25 dichotomous (Yes/No) items adapted from previous studies (see Online Resource 1). Each item corresponded to a barrier, and the following question was asked: "Please note whether each of the following causes might reduce the number of donations you make per year."

\subsection{Scale validation}

A principal component analysis (PCA) was used to validate the barrier scale (see Table 1). Given that items were dichotomous, the tetrachoric correlation matrix was used as input (Debelak \& Tran, 2013). Scale reliability was calculated using the KR-20 coefficient (Nunnally \& Bernstein, 1994).

The results in Table 1 show that:

- No barrier items were removed after the validation process.

- The PCA might be considered satisfactory, because $68.65 \%$ of the total variance was explained, thus exceeding the $60 \%$ threshold established by Hair et al. (2014).

- Factor loadings were very significant, as most of them exceeded 0.5 (Hair et al., 2014).

- Communalities were higher than 0.5 (excepting BARR8), therefore explaining more than half of the variability of the respondents' answers (Hair et al., 2014).

- The scale was reliable, since KR-20 values (global and for each dimension, except D4) were above or close to 0.7 (Nunnally \& Bernstein, 1994).

The PCA results show that there were several underlying dimensions in the proposed scale. These dimensions were labelled as "Informative barriers" (D1), "Intrinsic barriers" (D2), "Time-space barriers" (D3) and "Procedural barriers" (D4). Informative barriers included those barriers related to a lack of awareness about the donation process, location and operating times of donation venues, as well as the never-ending need for blood. Additionally, this dimension included the absence of promotional campaigns and reminders from the centers to donate again. Intrinsic barriers consisted of barriers related to the internal processes of individuals (i.e. 
Table 1 PCA results

\begin{tabular}{|c|c|c|c|c|c|}
\hline Barrier dimensions & COMM & D1 & $\mathrm{D} 2$ & D3 & D4 \\
\hline \multicolumn{6}{|l|}{ Informative barriers } \\
\hline BARR23 & 0.714 & 0.759 & 0.279 & 0.096 & 0.225 \\
\hline BARR3 & 0.689 & 0.733 & 0.357 & 0.151 & 0.042 \\
\hline BARR25 & 0.541 & 0.654 & 0.072 & 0.287 & 0.162 \\
\hline BARR2 & 0.683 & 0.627 & 0.182 & 0.505 & -0.034 \\
\hline BARR1 & 0.661 & 0.571 & 0.569 & 0.105 & -0.009 \\
\hline \multicolumn{6}{|l|}{ Intrinsic barriers } \\
\hline BARR18 & 0.902 & 0.160 & 0.934 & 0.052 & 0.025 \\
\hline BARR19 & 0.886 & 0.179 & 0.922 & 0.055 & 0.031 \\
\hline BARR20 & 0.860 & 0.151 & 0.913 & 0.051 & 0.025 \\
\hline BARR22 & 0.749 & 0.221 & 0.823 & 0.094 & 0.116 \\
\hline BARR5 & 0.720 & 0.104 & 0.808 & 0.132 & 0.197 \\
\hline BARR6 & 0.798 & 0.384 & 0.801 & 0.037 & 0.082 \\
\hline BARR21 & 0.639 & 0.038 & 0.777 & 0.117 & 0.142 \\
\hline BARR4 & 0.654 & 0.240 & 0.771 & 0.017 & 0.044 \\
\hline BARR16 & 0.667 & -0.136 & 0.753 & 0.274 & 0.080 \\
\hline BARR17 & 0.636 & -0.066 & 0.702 & 0.217 & 0.302 \\
\hline BARR7 & 0.490 & 0.314 & 0.589 & 0.061 & 0.201 \\
\hline \multicolumn{6}{|l|}{ Time-space barriers } \\
\hline BARR9 & 0.738 & 0.032 & -0.005 & 0.854 & 0.091 \\
\hline BARR11 & 0.807 & 0.178 & 0.214 & 0.844 & 0.134 \\
\hline BARR10 & 0.786 & 0.214 & 0.176 & 0.839 & 0.077 \\
\hline BARR8 & 0.415 & -0.096 & -0.148 & 0.584 & 0.208 \\
\hline BARR12 & 0.501 & 0.213 & 0.152 & 0.580 & 0.311 \\
\hline \multicolumn{6}{|l|}{ Procedural barriers } \\
\hline BARR14 & 0.705 & 0.263 & -0.019 & 0.031 & 0.796 \\
\hline BARR15 & 0.676 & -0.029 & 0.280 & 0.314 & 0.706 \\
\hline BARR13 & 0.673 & 0.015 & 0.217 & 0.409 & 0.677 \\
\hline BARR24 & 0.574 & 0.500 & 0.260 & 0.002 & 0.506 \\
\hline Eigenvalue & & 1.925 & 10.261 & 3.500 & 1.477 \\
\hline Partial explained variance (\%) & & 12.72 & 32.07 & 14.58 & 9.28 \\
\hline Total explained variance (\%) & 68.65 & & & & \\
\hline KR-20 (dimension) & & 0.729 & 0.887 & 0.725 & 0.556 \\
\hline Global KR-20 & 0.870 & & & & \\
\hline
\end{tabular}

Significant at $p \leq 0.05$

beliefs, perceptions) and donation fears (e.g. needles). Time-space barriers were related to the inconvenience of donation. Lastly, procedural barriers included aspects of the process itself which could discourage donation repetition. 
Table 2 Sample profile

\begin{tabular}{|c|c|c|}
\hline Characteristics & $\mathrm{N}$ & $\%$ \\
\hline \multicolumn{3}{|l|}{ Sex } \\
\hline Male & 2,640 & 49.3 \\
\hline Female & 2,713 & 50.7 \\
\hline \multicolumn{3}{|l|}{ Age (years) } \\
\hline $18-25$ & 782 & 14.6 \\
\hline $26-35$ & 1,243 & 23.2 \\
\hline $36-45$ & 1,613 & 30.1 \\
\hline $46-55$ & 1,350 & 25.2 \\
\hline$>55$ & 365 & 6.8 \\
\hline \multicolumn{3}{|l|}{ Education } \\
\hline No formal education or Primary & 705 & 13.2 \\
\hline Secondary & 2,092 & 39.1 \\
\hline University & 2,556 & 47.7 \\
\hline \multicolumn{3}{|l|}{ Total montly income (EUR) } \\
\hline$\leq 1,000$ & 1,204 & 22.5 \\
\hline $1,001-2,000$ & 2,412 & 45.1 \\
\hline $2,001-4,000$ & 1,392 & 26.0 \\
\hline$>4,000$ & 343 & 6.4 \\
\hline \multicolumn{3}{|l|}{ Donation frequency (per year) } \\
\hline One & 2,062 & 38.5 \\
\hline Twice & 2,044 & 38.2 \\
\hline Three or four times & 1,247 & 23.3 \\
\hline \multicolumn{3}{|l|}{ Donor experience (years) } \\
\hline$\leq 4$ & 1,998 & 37.3 \\
\hline $5-10$ & 1,636 & 30.6 \\
\hline$>10$ & 1,719 & 32.1 \\
\hline TOTAL & 5,353 & 100.0 \\
\hline
\end{tabular}

\section{Results}

\subsection{Sample profile}

Table 2 shows the sample profile, which was characterized by individuals older than 36 years-old $(62.1 \%)$, with secondary $(39.1 \%)$ or university $(47.7 \%)$ education, and a monthly income between 1,000 and 2,000 euros (45.1\%). In terms of sex, the sample was almost homogeneous ( $49.3 \%$ men vs. $50.7 \%$ women). Most respondents usually donated once $(38.5 \%)$ or twice $(38.2 \%)$ a year. Finally, most respondents were active donors for less than 10 years $(67.9 \%)$. 
Table 3 Descriptive statistics of barrier dimensions

\begin{tabular}{lcrllllrl}
\hline Barrier dimensions & Min & \multicolumn{1}{c}{ Max } & Mean & SD & Mean $(\%)$ & Q1 (\%) & Q2 (\%) & Q3 (\%) \\
\hline Informative barriers & 0.00 & 5.00 & 2.03 & 1.69 & 40.53 & 0.00 & 40.00 & 60.00 \\
Intrinsic barriers & 0.00 & 11.00 & 2.48 & 3.09 & 22.51 & 0.00 & 9.09 & 36.36 \\
Time-space barriers & 0.00 & 5.00 & 1.82 & 1.64 & 36.41 & 0.00 & 40.00 & 60.00 \\
Procedural barriers & 0.00 & 4.00 & 0.99 & 1.10 & 24.69 & 0.00 & 25.00 & 50.00 \\
\hline
\end{tabular}

\subsection{Descriptive analysis}

To analyze the relationship between the donor profile and the prevalence of barriers, four variables were created starting from the dimensions of the PCA. Each of these new variables corresponded to the sum of responses given by the respondents to the dichotomous items included in each dimension. Affirmative responses were assigned a numerical value of one, and negative responses were assigned a value of zero.

Table 3 shows the descriptive statistics of these new variables. Since each variable included a different number of items (between 4 and 11 barriers), the prevalence percentage ${ }^{4}$ of each variable was calculated for each respondent. Following these calculations, means and quartiles were extracted, showing that the most prevalent barriers were informative barriers $(\mathrm{M}=40.53 \%)$, followed by the time-space barriers $(\mathrm{M}=36.41 \%)$.

\subsection{Donor profile and the prevalence of donation barriers}

To explore how the donor profile affects the prevalence of donation barriers, $t$-tests or one-way ANOVA analyses were carried out, as well as the Cohen's $d$ statistic or Tukey's test, depending on the case (see Tables 4 and 5).

Table 4 shows the relationships between the sociodemographic profile (i.e. sex, age, education and income) and the prevalence of the four barrier dimensions (i.e. informative, intrinsic, time-space and procedural). The results indicate that sex affected all dimensions, except time-space barriers. Women had a higher prevalence of both informative and intrinsic barriers; and men had a higher prevalence of procedural barriers. However, the impact of these effects could not be considered significant because the values of the Cohen's $d$ statistic were not close to 0.8 .

Differences in means across all four barrier dimensions depending on age indicated a decreasing relationship, which means that the older the individual, the lower the prevalence of barriers. The Tukey's statistic indicated that the main differences were found between the 18-35 year-old donor groups ( 1 and 2 ) and the other groups (3, 4 and 5).

\footnotetext{
${ }^{4}$ For instance, in the informative barriers dimension, if the respondent selected two items (from a total of 5), the prevalence of such barriers was $40.0 \%$.
} 


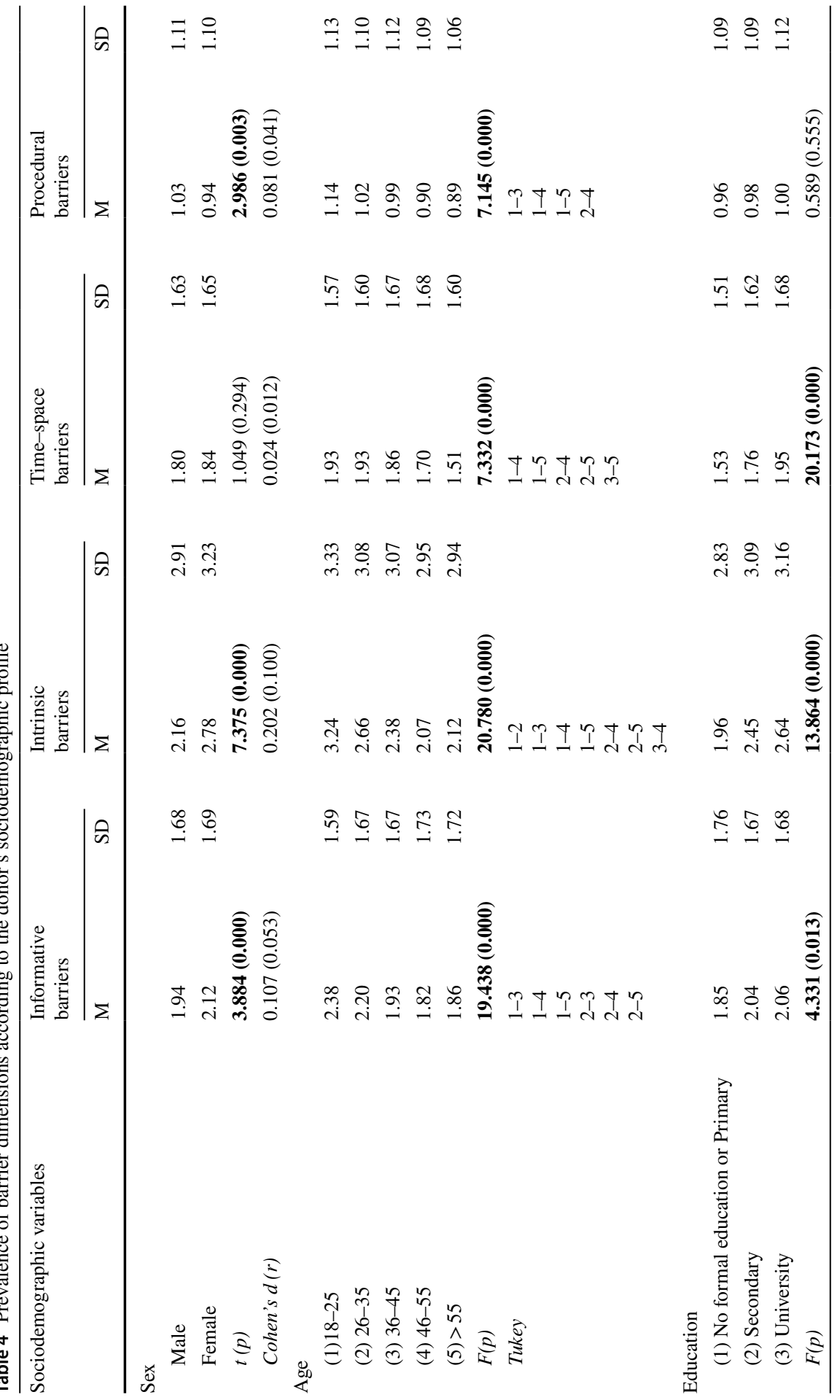




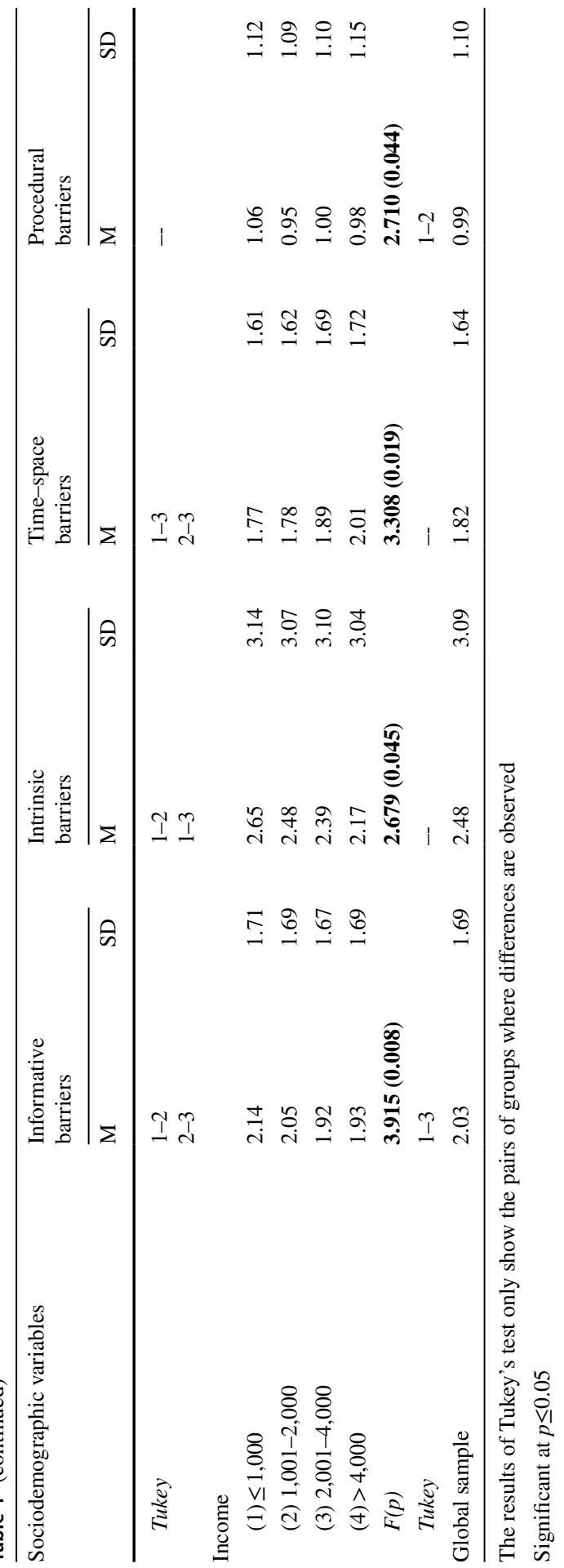




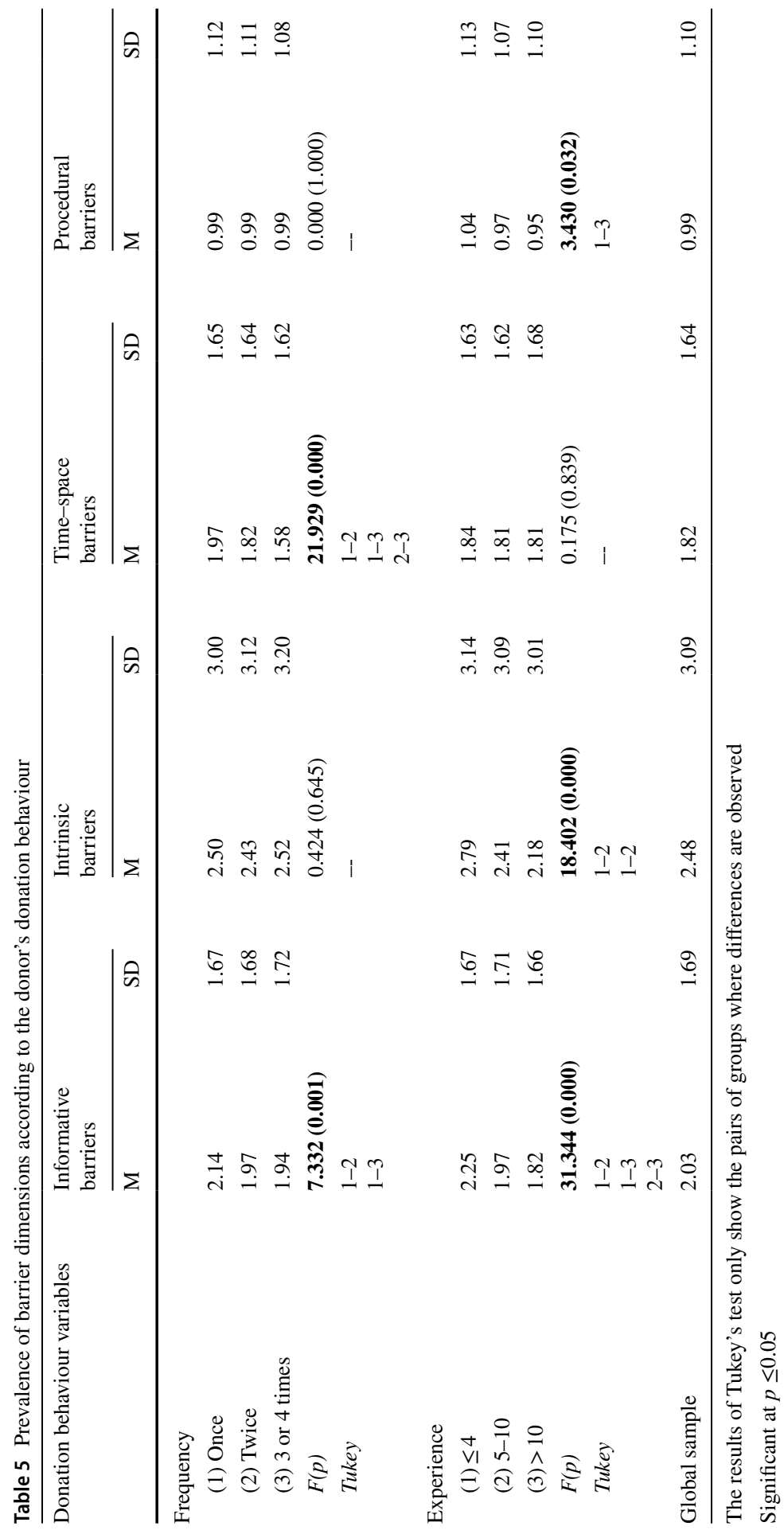


Education affected the prevalence of three barrier dimensions: informative barriers, intrinsic barriers and time-space barriers. This relationship was direct and positive, that is, the higher the education, the higher the prevalence of barriers. According to the values of the Tukey's statistic, the main differences were found between donors with no education or with primary education, and donors with secondary and university education, with the former group having lower prevalence values.

Finally, income affected the prevalence of all barrier dimensions. This relationship was inversely proportional for both informative and intrinsic barriers, which means that the higher the income, the lower the prevalence of such barriers. In the case of time-space barriers, the effect was direct, i.e. their prevalence increased with income. Lastly, the relationship between income and procedural barriers, although statistically significant, did not show a clear trend. The Tukey's statistic shows that the differences, although minor, were among donors perceiving less than 1,000 euros compared to the other groups.

Table 5 shows how donation behavior (namely donation frequency and donor experience) influences the prevalence of the four barrier dimensions. The results indicate an inverse relationship between both informative and time-space barriers with donation frequency. The Tukey's statistic shows that the main differences occurred between the donors who donated once a year compared to the other two groups, with the former having a greater prevalence of informative and time-space barriers.

The data indicate that donor experience influenced all barrier dimensions, except time-space barriers. There was an inverse relationship in the three cases, i.e. the greater the experience, the lower the prevalence. Here again, the main differences were found among less experienced donors.

\section{Discussion}

In order to meet the demand for blood, blood transfusion centers rely on donor retention strategies. One of the advantages of retention is that it involves significant cost savings for centers, because retaining a current donor is substantially more costefficient that recruiting a new donor (Gemelli et al., 2017). To ensure that marketing efforts achieve their objectives, blood transfusion centers must analyze their donor pools, in order to know which the most prominent donation barriers are. At the same time, to adequately know who to target the designed marketing actions, centers must be aware of the most salient characteristics (both sociodemographic and donationrelated) of their pools (Glynn et al., 2002).

A barrier scale was designed and validated to assist centers in such donor management. This scale itself constitutes, from a theoretical perspective, the first contribution of the present study, as it arises as a possible solution to the absence of an agreed catalogue of blood donation barriers. The designed 25-item scale is the result of grouping all barriers identified in the existing blood donor behavior literature under a same naming, according to their shared meaning. As the scale includes barriers of diverse typology, it is possible to analyze its subyacent dimensionality. In this way, barrier items could be grouped in common categories, as previous authors 
have attempted (e.g. Polonsky et al., 2015; Zaller et al., 2005). Therefore, the scale, holistic and integrative in nature, constitutes a useful measurement tool for blood transfusion centers to identify which individual barriers or barrier typologies affect their donors the most.

This scale was used to analyze the prevalence of donation barriers in a sample of active blood donors in the Canary Islands (Spain). The most prevalent barriers were, firstly, informative barriers and, secondly, time-space barriers. The low prevalence of intrinsic barriers among active donors is due to the fact that these donors are familiar with the donation process and equipment, which significantly reduces fear and, consequently, the occurrence of adverse reactions.

This study also contributes to statistically show how the donor profile influences the prevalence of the different barrier dimensions. Additionally, this study expands the knowledge on the influence of less studied variables such as education, income level and donation frequency (refer to Online Resource 1).

In consonance with previous literature, women experience more internal barriers (Hupfer et al., 2005; Schreiber et al., 2006), while men are more externally deterred. At the same time, the youngest donors (18-35 years-old) are the most inhibited in general. Results show that barriers decrease as age increases (Charbonneau et al., 2016), which is most likely related to donor experience. Higher education and income lead to higher donation barriers, especially those related to the time factor. Variables related to donation behavior also affect the prevalence of barriers: donors who make less donations per year are the least informed and have the most time-space restrictions, and those who have donated blood the longest are those who experience the fewest barriers. Therefore, this research shows that the donors most affected by blood donation barriers are young adults (18-35 years-old), with university studies and a higher income level, who generally donate once or twice a year and who have less than four years of donor experience. Blood transfusion centers should design social marketing actions aimed at these donors to eliminate, or at least reduce, the barriers that most affect them (Barkworth et al., 2002). Ultimately, these donors would be able to stay in the system longer, as well as to increase the number of donations they make per year. Additionally, given that the population is progressively aging, it is critical that donor pools have enough young active donors to ensure the long-term maintenance of the donation system (Misje et al., 2008; Yuan et al., 2011).

Thus, as practical implications, this study recommends blood transfusion centers to focus preferably on informative and procedural barriers, as their extrinsic nature facilitates interventions on them (Boenigk et al., 2011). Given the profile of the most affected donors, as well as the possibilities offered by technological advances (Trenholm, 2017), developing active, two-way communication on social networks or implementing direct marketing actions (e.g. e-mailing or instantmessaging) would allow centers to more effectively deliver the desired information on, for example, upcoming collection campaigns. As far as procedural barriers are concerned, although certain aspects of the donation process are regulated to ensure the safety of both donors and recipients, measures to reduce these barriers do exist. For example, by automating the pre-donation health questionnaire, so that donors only need to update specific items; or by offering the possibility of filling the questionnaire in online before a donation. A complete and updated 
donor database is essential to achieve this, as well as enhancing the use of customer relationship management (CRM) sytems to improve donor communication and campaign coordination. On the other hand, if waiting times cannot be reduced for economic reasons, the wait could be made more bearable by offering distractions such as reading material, visual projections, etc. Finally, regarding time-space barriers, although some of them are intrinsic to the individual, blood transfusion centers could facilitate donation by organizing mobile collections in workplaces. In fact, in their study, Schreiber et al. (2006) found that $46.0 \%$ of respondents considered the workplace to be the most convenient place to donate. Furthermore, carrying out the process in a familiar environment, away from the healthcare environment, could possibly minimize the aversion to donating, thus minimizing some intrinsic barriers.

The main limitation of this study refers to the studied population, which are active donors living in the Canary Islands (Spain). It would be interesting to replicate the study in other Spanish regions, or even in other countries, for comparative purposes. Furthermore, as a future line of research, the authors propose to replicate the study in geographical contexts where the donation system is not voluntary (e.g. remunerated, replacement), because in Spain, the only legal donation modality is the voluntary one.

Supplementary Information The online version contains supplementary material available at https://doi. org/10.1007/s12208-021-00303-5.

Acknowledgements This research received financial support from the Spanish Ministry of Economy and Competitiveness (Project ECO2015-64875-R).

Funding Open Access funding provided thanks to the CRUE-CSIC agreement with Springer Nature. This research received financial support from the Spanish Ministry of Economy and Competitiveness (Project ECO2015-64875-R).

Data availability The data that support the findings of this study are available on request from the corresponding author. The data are not publicly available due to privacy restrictions.

Code availability Not applicable.

\section{Declarations}

Ethics approval This study was exempted from the requirement for approval by the responsible ethics committee due to its nature (participants were not patients, and their participation was voluntary and anonymous).

Consent to participate The participation in the study was voluntary. Therefore, respondents' willingness to complete the questionnaire indicated their consent to participate.

Consent for publication The questionnaire was completely anonymous. Therefore, there is no identifiable information requiring consent for publication.

Conflicts of interest All authors declare that they have no conflicts of interests.

Open Access This article is licensed under a Creative Commons Attribution 4.0 International License, which permits use, sharing, adaptation, distribution and reproduction in any medium or format, as long as 
you give appropriate credit to the original author(s) and the source, provide a link to the Creative Commons licence, and indicate if changes were made. The images or other third party material in this article are included in the article's Creative Commons licence, unless indicated otherwise in a credit line to the material. If material is not included in the article's Creative Commons licence and your intended use is not permitted by statutory regulation or exceeds the permitted use, you will need to obtain permission directly from the copyright holder. To view a copy of this licence, visit http://creativecommons.org/licen ses/by/4.0/.

\section{References}

Alinon, K., Gbati, K., Sorum, P. C., \& Mullet, E. (2014). Emotional-motivational barriers to blood donation among Togolese adults: A structural approach. Transfusion Medicine, 24, 21-26. https://doi.org/10.1111/tme.12082.

Bani, M., Strepparava, M., \& Giussani, B. (2014). Gender differences and frequency of whole blood donation in Italian donors: Even though I want to, I cannot? Transfusion and Apheresis Science, 50, 81-86. https://doi.org/10.1016/j.transci.2013.11.001.

Barkworth, L., Hibbert, S., Horne, S., \& Tagg, S. (2002). Giving at risk ? Examining perceived risk and blood donation behaviour. Journal of Marketing Management, 18(9-10), 905-922. https:// doi.org/10.1362/0267257012930376.

Bednall, T. C., \& Bove, L. L. (2011). Donating blood: A meta-analytic review of self-reported motivators and deterrents. Transfusion Medicine Reviews, 25(4), 317-334. https://doi.org/10.1016/j. tmrv.2011.04.005.

Beerli-Palacio, A., \& Martín-Santana, J. D. (2015). How to increase blood donation by social marketing. International Review on Public and Nonprofit Marketing, 12, 253-266. https://doi.org/10. 1007/s12208-015-0133-8.

Boenigk, S., \& Leipnitz, S. (2016). Acquiring potential blood donors in large cities: A preferencebased donor segmentation study. Journal of Nonprofit \& Public Sector Marketing, 28(4), 364393. https://doi.org/10.1080/10495142.2016.1238330.

Boenigk, S., Leipnitz, S., \& Scherhag, C. (2011). Altruistic values, satisfaction and loyalty among first-time blood donors. International Journal of Nonprofit and Voluntary Sector Marketing, 16, 356-370. https://doi.org/10.1002/nvsm.433.

Carter, M. C., Wilson, J., Redpath, G. S., Hayes, P., \& Mitchell, C. (2011). Donor recruitment in the 21st century: Challenges and lessons learned in the first decade. Transfusion and Apheresis Science, 45, 31-43. https://doi.org/10.1016/j.transci.2011.06.001.

Charbonneau, J., Cloutier, M.-S., \& Carrier, É. (2016). Why do blood donors lapse or reduce their donation's frequency? Transfusion Medicine Reviews, 30, 1-5. https://doi.org/10.1016/j.tmrv. 2015.12.001.

Debelak, R., \& Tran, U. S. (2013). Principal component analysis of smoothed tetrachoric correlation matrices as a measure of dimensionality. Educational and Psychological Measurement, 73(1), 63-77. https://doi.org/10.1177/0013164412457366.

Ditto, B., Byrne, N., Holly, C. D., \& Balegh, S. (2014). Social contagion of vasovagal reactions in the blood collection clinic: A possible example of mass psychogenic illness. Health Psychology, 33(7), 639-645. https://doi.org/10.1037/hea0000053.

Duboz, P., \& Cunéo, B. (2010). How barriers to blood donation differ between lapsed donors and nondonors in France. Transfusion Medicine, 20, 227-236. https://doi.org/10.1111/j.1365-3148.2010. 00998.x.

France, C. R., \& France, J. L. (2018). Fear of donation-related stimuli is reported across different levels of donation experience. Transfusion, 58, 113-120. https://doi.org/10.1111/trf.14382.

France, C. R., France, J. L., Wissel, M. E., Ditto, B., Dickert, T., \& Himawan, L. K. (2013). Donor anxiety, needle pain, and syncopal reactions combine to determine retention: A path analysis of two-year donor return data. Transfusion, 53, 1992-2000. https://doi.org/10.1111/trf.12069.

France, C. R., Rader, A., \& Carlson, B. W. (2005). Donors who react may not come back: Analysis of repeat donation as a function of phlebotomist ratings of vasovagal reactions. Transfusion and Apheresis Science, 33, 99-106. https://doi.org/10.1016/j.transci.2005.02.005. 
Gemelli, C. N., Hayman, J., \& Waller, D. (2017). Frequent whole blood donors: Understanding this population and predictors of lapse. Transfusion, 57, 108-114. https://doi.org/10.1111/trf.13874.

Glynn, S. A., Kleinman, S. H., Schreiber, G. B., Zuck, T., Mc Combs, S., Bethel, J., Garratty, G., \& Williams, A. E. (2002). Motivations to donate blood: Demographic comparisons. Transfusion, 42, 216-225. https://doi.org/10.1046/j.1537-2995.2002.00008.x.

Godin, G., Sheeran, P., Conner, M., Germain, M., Blondeau, D., Gagné, C., Beaulieu, D., \& Naccache, P. H. (2005). Factors explaining the intention to give blood among the general population. Vox Sanguinis, 89, 140-149. https://doi.org/10.1111/j.1423-0410.2005.00674.x.

Hair, J. F., Black, W. C., Babin, B. J., \& Anderson, R. E. (2014). Multivariate Data Analysis. Pearson.

Huis in 't Veld, E. M. J., de Kort, W. L. A. M., \& Merz, E.-M. (2019). Determinants of blood donation willingness in the European Union: A cross-country perspective on perceived transfusion safety, concerns, and incentives. Transfusion, 59, 1273-1282. https://doi.org/10.1111/trf.15209.

Hupfer, M. E., Taylor, D. W., \& Letwin, J. A. (2005). Understanding Canadian student motivations and beliefs about giving blood. Transfusion, 45, 149-161. https://doi.org/10.1111/j.1537-2995. 2004.03374.x.

James, A. B., Schreiber, G. B., Hillyer, C. D., \& Shaz, B. H. (2013). Blood donations motivators and barriers: A descriptive study of African American and white voters. Transfusion and Apheresis Science, 48, 87-93. https://doi.org/10.1016/j.transci.2012.07.005.

Kalargirou, A. A., Beloukas, A. I., Kosma, A. G., Nanou, C. I., Saridi, M. I., \& Kriebardis, A. G. (2014). Attitudes and behaviours of Greeks concerning blood donation: Recruitment and retention campaigns should be focused on need rather than altruism. Blood Transfusion, 12, 320-329. https://doi.org/10.2450/2014.0203-13.

Klinkenberg, E. F., Romeijn, B., de Kort, W. L., \& Merz, E. M. (2018). Reasons to end the donor career: A quantitative study among stopped blood donors in the Netherlands. Transfusion Medicine, 28, 200-207. https://doi.org/10.1111/tme.12442.

Marantidou, O., Loukopoulou, L., Zervou, E., Martinis, G., Egglezou, A., Fountouli, P., Dimoxenous, P., Parara, M., Gavalaki, M., \& Maniatis, A. (2007). Factors that motivate and hinder blood donation in Greece. Transfusion Medicine, 17, 443-450. https://doi.org/10.1111/j.1365-3148. 2007.00797.x.

Martín-Santana, J. D., \& Beerli-Palacio, A. (2012). Achieving donor repetition and motivation by block leaders among current blood donors. Transfusion and Apheresis Science, 47, 337-343. https://doi.org/10.1016/j.transci.2012.05.015.

Martín-Santana, J. D., Beerli-Palacio, A., \& Romero-Domínguez, L. (2020). Recruitment strategies: Non-donor segmentation based on intrinsic and extrinsic stimuli. Vox Sanguinis, 115(1), 47-59. https://doi.org/10.1111/vox.12858.

Martín-Santana, J. D., Reinares-Lara, E., \& Reinares-Lara, P. (2018). Using radio advertising to promote blood donation. Journal of Nonprofit and Public Sector Marketing, 30(1), 52-73. https:// doi.org/10.1080/10495142.2017.1326340.

Misje, A. H., Bosnes, V., \& Heier, H. E. (2008). Recruiting and retaining young people as voluntary blood donors. Vox Sanguinis, 94, 119-124. https://doi.org/10.1111/j.1423-0410.2007.01004.x.

Mokwa, M. P. (1990). The policy characteristics and organizational dynamics of social marketing. In S. H. Fine (Ed.), Social marketing: Promoting the causes of public and nonprofit agencies (pp. 43-55). Allyn \& Ba.

Moussaoui, L. S., Naef, D., Tissot, J.-D., \& Desrichard, O. (2016). "Save lives" arguments might not be as effective as you think: A randomized field experiment on blood donation. Transfusion Clinique Et Biologique, 23, 59-63. https://doi.org/10.1016/j.tracli.2016.03.003.

Nunnally, J. C., \& Bernstein, I. H. (1994). Psychometric theory (3rd ed). McGraw Hill, Inc.

Piersma, T. W., Bekkers, R., Klinkenberg, E. F., De Kort, W. L. A. M., \& Merz, E.-M. (2017). Individual, contextual and network characteristics of blood donors and non-donors: A systematic review of recent literature. Blood Transfusion, 15, 382-397. https://doi.org/10.2450/2017.0064-17.

Polonsky, M., Francis, K., \& Renzaho, A. M. N. (2015). Is removing blood donation barriers a donation facilitator? Journal of Social Marketing, 5(3), 190-205. https://doi.org/10.1108/ JSOCM-08-2014-0054.

Rodrigues, R. G., \& Carlos, V. S. (2020). Attracting potential blood donors: The role of personality and social marketing. International Journal of Nonprofit and Voluntary Sector Marketing, e1694. https://doi.org/10.1002/nvsm.1694.

Schreiber, G. B., Schlumpf, K. S., Glynn, S. A., Wright, D. J., Tu, Y., King, M. R., Higgins, M. J., Kessler, D. A., Gilcher, R., Nass, C. C., \& Guiltinan, A. M. (2006). Convenience, the bane of 
our existence, and other barriers to donating. Transfusion, 46, 545-553. https://doi.org/10.1111/j. 1537-2995.2006.00757.x.

Shaz, B. H., James, A. B., Demmons, D. G., Schreiber, G. B., \& Hillyer, C. D. (2010). The African American church as a donation site: Motivations and barriers. Transfusion, 50, 1240-1248. https://doi.org/10.1111/j.1537-2995.2009.02570.x.

Solomon, G. D. (2012). Segmentation and communications to solve the blood shortage: An exploration of the problem with recommendations. VOLUNTAS: International Journal of Voluntary and Nonprofit Organizations, 23, 415-433. https://doi.org/10.1007/s11266-010-9179-8.

Sundermann, L. M., Boenigk, S., \& Willems, J. (2017). Under blood pressure - Differentiated versus undifferentiated marketing to increase blood donations. International Review on Public and Nonprofit Marketing. https://doi.org/10.1007/s12208-017-0174-2.

Tey, Y. S., Arsil, P., Brindal, M., Lee, S. K., \& Teoh, C. T. (2020). Motivation structures of blood donation: A means-end chain approach. International Journal of Health Economics and Management, 20, 41-54. https://doi.org/10.1007/s10754-019-09269-8.

Trenholm, I. (2017). Donors and technology - How far should we go? Transfusion Medicine, 27, 81-83. https://doi.org/10.1111/tme.12404.

Vavić, N., Pagliariccio, A., Bulajić, M., Marinozzi, M., Miletić, G., \& Vlatković, A. (2012). Blood donor satisfaction and the weak link in the chain of donation process. Transfusion and Apheresis Science, 47, 171-177. https://doi.org/10.1016/j.transci.2012.06.025.

Yuan, S., Hoffman, M., Lu, Q., Goldfinger, D., \& Ziman, A. (2011). Motivating factors and deterrents for blood donation among donors at a university campus-based collection center. Transfusion, 51, 2438-2444. https://doi.org/10.1111/j.1537-2995.2011.03174.x.

Zaller, N., Nelson, K., Ness, P., Wen, G., Bai, X., \& Shan, H. (2005). Knowledge, attitude and practice survey regarding blood donation in a Northwestern Chinese city. Transfusion Medicine, 15, 277286. https://doi.org/10.1111/j.0958-7578.2005.00589.x.

Zucoloto, M. L., Gonçalez, T., Menezes, N. P., McFarland, W., Custer, B., \& Martinez, E. Z. (2019). Fear of blood, injections and fainting as barriers to blood donation in Brazil. Vox Sanguinis, 114, 38-46. https://doi.org/10.1111/vox.12728.

Publisher's note Springer Nature remains neutral with regard to jurisdictional claims in published maps and institutional affiliations. 